\title{
Trigeminal Neuralgia Type 1: Earlier Microvascular Decompression is Associated with Improved Outcome
}

\author{
Doortje C Engel ${ }^{1,2 *}$, Jean-Yves Fournier ${ }^{1}$, Cem Yetimoglu ${ }^{1}$ and Sarah R Haile ${ }^{3}$ \\ ${ }^{1}$ Department of Neurosurgery, Cantonal Hospital St. Gall, Switzerland \\ ${ }^{3}$ Department of Neurosurgery, University Hospital Tuebingen, Germany \\ ${ }^{2}$ Epidemiology, Biostatistics and Prevention Institute, University of Zurich, Switzerland
}

\begin{abstract}
Background: Medication therapy is commonly accepted as the initial treatment of trigeminal neuralgia (TN). Microvascular decompression (MVD) is the surgical treatment with the highest efficacy, but is considered as last tier therapy for patients with medication refractory pain or for those with unbearable side effects. The aim of this study was to investigate the association of symptom duration on outcome.
\end{abstract}

Methods: A retrospective study was conducted from 2001 through 2012. Patients were categorized according to Burchiel's "Classification scheme for facial pains commonly encountered in neurosurgical practice". Demographical, disease and treatment data as well as surgical data including complications and outcome were recorded and analyzed.

Results: In total, 65 patients were included. Distribution of diagnoses was as follows: TN type 1 (>50\% episodic pain) $n=54$, TN type $2(>50 \%$ constant pain) $n=4$, neuropathic $T N n=1$, symptomatic $T N$ due to multiple sclerosis $n=3$, post herpetic $\mathrm{n}=2$. Onset of disease to surgery was on average 7 years $(<1-21$ years). Shorter time from disease onset to surgery had a statistically significant association with a pain-free outcome in only TN type 1 patients ( 6 vs. 13 years, $p=0.01$ ). Overall success rate in TN1 was $88.9 \%$. Overall mortality and morbidity rate were $3 \%$. Overall complication rate was $13.5 \%$.

Conclusion: Earlier MVD was significantly associated with better outcome. Patients should be informed about the option of MVD at an early stage of disease.

Keywords: Trigeminal neuralgia; Microvascular decompression; Treatment strategy; Outcome

\section{Introduction}

As a mean to re-establish human capacity and human function in society, rehabilitation is related to an effort to restore for a good condition, including restoring function and re-integrating to communities [1,2]. Psychological rehabilitation of terrorism offenders focuses on character building and well-being, in order to have more peaceful state of mind and favorable attitude to successfully contribute to society [1]. Orientation of psychological development activities is giving opportunity to offenders to transform into more positive individuals [3].

Practically, there are two types of rehabilitation to terrorism offenders. The first includes isolation techniques ('exclusiveness'), which would isolate terrorism offenders in some special circumstances $[4,5]$. The fundamental reason for exclusiveness is related to the prevention of the spread of ideology that justifies violence. The use of sacred texts to justify violence [6,7] and the wide range of terrorism network are seen to be hazardous $[8,9]$. The second type of rehabilitation is related to allowing terrorism offenders to blend or meet with general criminal inmates or visitors (e.g. family) under certain circumstances ("inclusiveness"), in order to encounter Humans Rights concern [10]. Both exclusiveness and inclusiveness include counseling session, assistance (e.g. programs for family), exposure to new learning experiences, dialogues with several favorable source persons, and empowerment facilitation [11-17].

To address whether inclusiveness and exclusiveness is the best application in rehabilitating the psychology of terrorism offenders, this research will examine steps in rehabilitating religious terrorism offenders, psychological transformation process and observed positive behavioral changes in religious terrorism offenders. The study aims to figure out the effective implementations of inclusiveness and exclusiveness on religious terrorism offenders at prisons. As the discussion about rehabilitating terrorism offenders will always be linked to the motivation of terrorism, this study will review motives of religious terrorism offenders, causes of religious terrorism, and shared process of psychological transformation within religious terrorism offenders.

\section{Materials and Methods}

A retrospective study was conducted including all patients treated by MVD for TN in our institution from 2001 to 2012. Patients were categorized according to Burchiel's [18] "Classification scheme for facial pains commonly used encountered in neurosurgical practice" (Table 1). All patients signed the local official informed consent for the surgical procedure.

Three surgeons performed the procedure, which consisted of decompression accordingly to previous descriptions [19-21]. In short, a detailed exploration of the cisternal portion of the nerve was conducted to avoid missing multiple vessel conflicts. Teflon ${ }^{\circledR}$ (Johnson \& Johnson, Ltd.) was used as interposition material between the vessels

\begin{tabular}{|c|c|c|}
\hline Diagnosis & History & $\mathbf{N}=65$ \\
\hline Trigeminal neuralgia, Type 1 & $>50 \%$ episodic pain (spontaneous onset) & 55 \\
\hline Trigeminal neuralgia, Type 2 & $>50 \%$ constant pain (spontaneous onset) & 4 \\
\hline Trigeminal neuropathic pain & Unintentional, incidental trauma (injury) & 1 \\
\hline Trigeminal deafferentation pain & Intentional deafferentation (injury) & 0 \\
\hline Symptomatic trigeminal neuralgia & Multiple sclerosis & 3 \\
\hline
\end{tabular}

Table 1: Distribution of diagnoses according to Burchiel's [18] classification of facia pain.

*Corresponding author: Doortje C. Engel, MD, PhD, MBA, Department of Neurosurgery, University Hospital Tuebingen, Hoppe-Seyler-Strasse 3, D-72076 Tuebingen, Germany; Tel:+4970712986679; E-mail: doortje.engel@med.uni-tuebingen.de

Received March 28, 2018; Accepted April 27, 2018; Published April 30, 2018

Citation: Engel DC, Fournier JY, Yetimoglu C, Haile SR (2018) Trigeminal Neuralgia Type 1: Earlier Microvascular Decompression is Associated with Improved Outcome. Int J Neurorehabilitation 5: 307. doi: 10.4172/2376-0281.1000307

Copyright: $\odot 2018$ Engel DC, et al. This is an open-access article distributed unde the terms of the Creative Commons Attribution License, which permits unrestricted use, distribution, and reproduction in any medium, provided the original author and source are credited. 
and the trigeminal nerve. Avoiding contact between Teflon and nerve, as recommended by Sindou et al. [20], was not possible in all cases [22]. Clinical characteristics, disease specific, procedural specific data and prior treatments were recorded. An outpatient checkup was conducted in all patients 4-5 weeks postoperatively. Further followup was at variable time points. Long-term outcome was recorded as follows for pain: pain free, improved, unchanged, worse. A worsening due to complications or other reasons and death were recorded separately. Special attention was given to postoperative complications, i.e., cerebellar symptoms, facial hypoesthesia, facial palsy, hearing loss, tinnitus, persisting wound pain ( $>3$ months), persistent cerebrospinal fluid (CSF) fistula, wound infection and postoperative hemorrhage.

The outcome groups were analyzed for time from disease onset to surgery using the t-tests and linear regression. Statistical analysis was performed with " $\mathrm{R}$ " software version 2.12.2 (The R Foundation for Statistical Computing).

\section{Results}

\section{Clinical characteristics}

A total of 65 patients have undergone 74 MVDs. One patient was operated bilaterally. Thirty-five patients were female. Distribution of diagnoses is shown in Table 1. Mean age at onset of disease was 57 years (range 26 to 79). Mean age at the time of surgery was 64 years (range 30-84). As for the involved trigeminal segments, the first branch (V1) was involved in 23 cases $(35.4 \%)$, the V2 in 49 cases $(75.4 \%)$ and the $\mathrm{V} 3$ in 23 (35.4\%). In 3 patients (4.6\%) all branches were involved, in 13 patients (20\%) the branches V2 and V3 and in $13(20 \%)$ the branches $\mathrm{V} 1$ and $\mathrm{V} 2$.

\section{Treatment}

Preoperative invasive procedures for trigeminal neuralgia were conducted in 9 patients (13.8\%); 6 (9.2\%) received a glycerol rhizotomy and $3(4.6 \%)$ a thermorhizotomy. These patients were older than patients that did receive only medical therapy (mean age 65 and 56 years, respectively). One of these pre-treated patients did not improve postoperatively, the other one died of pneumonia. Mean duration from onset of symptoms to MVD was 7 years (range 3.5 months-21 years). During all operations a conflicting vessel, a vein, an artery or both, was identified.

\section{Complications}

Complications were noted in 10 patients and 74 operations leading to an overall complication rate of (13.5\%). One patient suffered from a superficial wound infection (1.35\%), which was treated with antibiotics. Four patients developed a persistent CSF fistula (5.4\%), which was all diagnosed by rhinorrhea. All these patients were re-operated without reopening the intradural space. Other complications consisted of temporary hearing reduction due to haematotympanum ( $\mathrm{n}=1,1.35 \%)$, permanent one-sided hearing loss $(n=1,1.35 \%)$ and permanent facial hypaesthesia $(n=1,1.35 \%)$. There were no cases of anesthesia dolorosa or decreased corneal reflex. Mortality was 3\% $(n=2)$. One patient died of pneumonia 2 weeks after surgery. This patient was $>75$ years at the time of diagnosis and $>90$ at the time of surgery. One patient, age $>75$ years, died due to bleeding from a venous aneurysm of $5 \times 4 \mathrm{~mm}$ from an AVM found at autopsy. The AVM was not identified in the pre-op scans.

\section{Clinical outcome}

Mean follow-up time in TN patients was 15 months (range 1-82 months). The initial success rate (improvement and complete recovery) in all $\mathrm{TN}$ patients was $92.1 \%$. The overall success rate (improvement and complete recovery) was $88.9 \%$ calculated for the last visit of the patient. Initial outcome divided between typical and atypical $\mathrm{TN}$ is shown in Table 2. No patient expressed a worsening of the preoperative symptoms. Fourteen patients $(22 \%)$ suffered from a recurrence after having expressed a significant improvement of their symptoms. Eight patients (12.7\%) underwent a second MVD for their recurrence, after which $6(75 \%)$ were pain-free and 1 (25\%) experienced a significant improvement and 1 (25\%) retained the same symptoms. Four recurrences occurred within 1 year after MVD, the other four between 2 and 4 years. Time to reoperation was on average 2 years (range 3 weeks- 6 years). The patient that was re-operated after 3 weeks had been pain free for 3 days after the operation. When the patient reported a recurrence, the surgeon suspected a dislocation of the interposition material. Intraoperative, the two ventrally decompressed parallel arteries were still correctly decompressed. A third artery dorsal of the DREZ was found and decompressed consequently.

One patient was treated afterwards by glycerol infiltration, and another patient rejected any further surgical treatment. High age, female sex and pre-treatment by glycerol or thermorhizotomy were not associated with worse outcome.

\section{Duration of symptoms in TN1 patients}

Shorter duration of symptoms until MVD was significantly associated with better final outcome in the $53 \mathrm{TN} 1$ cases as shown in Figure 1. Patients in the "pain free" group were operated on average

\begin{tabular}{|c|c|c|c|}
\hline & $\begin{array}{c}\text { TN 1 } \\
\mathbf{n = 5 3}\end{array}$ & TN other $\mathbf{n = 1 0}$ & $\begin{array}{c}\text { Overall } \mathbf{n = 6 3} \\
\mathbf{( \% )}\end{array}$ \\
\hline No effect & 4 & 1 & $5(7.9)$ \\
\hline Improvement & 8 & 8 & $16(25.4)$ \\
\hline Complete recovery & 41 & 1 & $42(66.7)$ \\
\hline
\end{tabular}

Table 2: Initial outcome after operation.

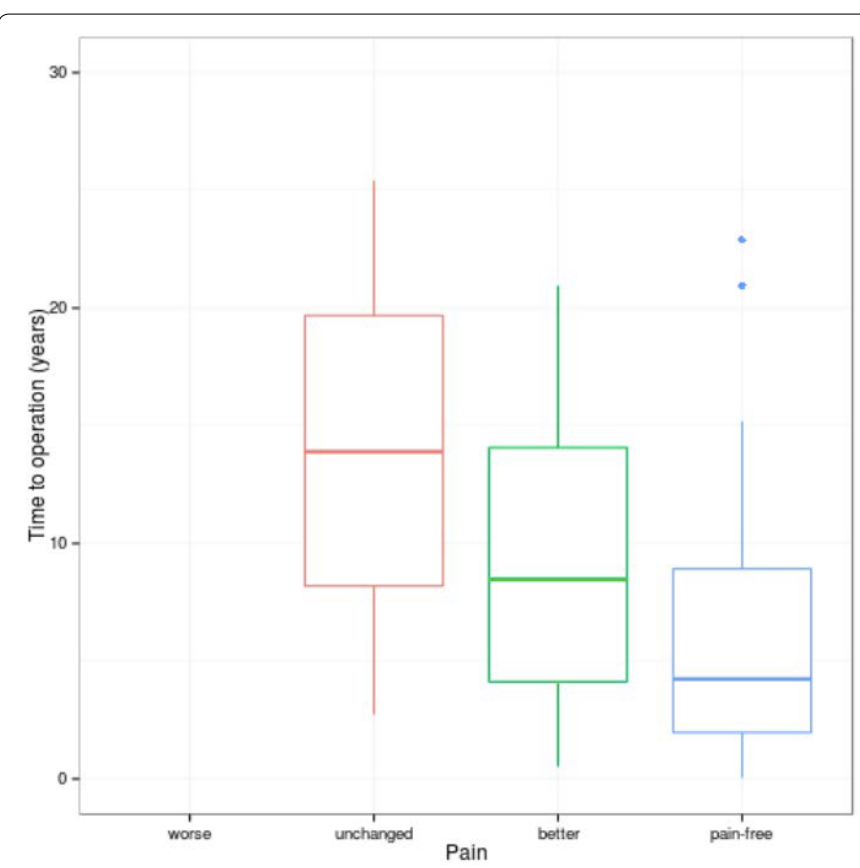

Note: Patients with an unchanged pain outcome (red, $n=5)$ were operated later than patients with an improved pain outcome (green, $n=8$ ) and significantly later than patients with a pain-free outcome (blue, $n=40,{ }^{*} p<0.01$ ). Two patients showed a pain-free outcome after 20 years of disease ( 2 blue dots)

Figure 1: Correlation of time to surgery and outcome. 
after 6.0 years, whilst patients in the "unchanged" group were operated on average 12.8 years after onset of disease $(\mathrm{p}=0.01)$. Mean age did not differ significantly (unchanged: 65.3; improved: 60.8; pain free 64.1 years).

\section{Discussion}

Our findings add to existing body of evidence showing that shorter symptom duration of TN1 to MVD is significantly associated with a better outcome. The existing literature on this matter is either in agreement with our findings [11-16,19] or did not find any correlations $[9,10,20,23-25]$.

As medication therapy is the first line therapy, patients are often referred for surgical treatment late in the course of disease. Next to that, duration of medication therapy is possibly prolonged as several drugs or drug combinations are tested and the number of possible drugs is still growing [26]. This leads to a delayed referral for surgical treatment in spite of a positive association of early MVD and better outcome. The association of better outcome and other surgical treatments have not been scope of this study as several investigations show that MVD is the procedure with the lowest recurrence and highest patient satisfaction rate $[4,17,27,28]$. On the other hand, medical treatment possibilities are limited with decreasing hepatic and renal function with increasing age [1]. Therefore surgical treatment can be considered a valid next-step option after pharmacological treatment in the elderly. Our recurrence rate, rate of pain relief and complication rates are similar as described previously in the literature [20,29-31]. Despite this recurrence rate $75 \%$ of the patients that suffered a recurrence could be treated with a satisfactory outcome.

A mortality rate of $3 \%$ is higher than described in the existing literature $(0.5 \%$; [32]). Both patients were elderly and had symptom durations of 5 and 12 years.

Although larger series showed no significant differences in complications among elderly patients (0-5\%; [33-35]), our mortality cases were $>75$ years of age. The unidentified AVM was most likely to be age-independent, however a postoperative pneumonia might have been avoided by another treatment option without general anesthesia and quicker independent mobility of the patient, e.g. radiosurgery.

In our study many patients received medical treatment for 10-20 years. A published comparison of medication treatment (carbamazepine) with MVD showed that medication treatment was less expensive at the beginning of the disease and that this effect faded away over time. In the end MVD was the cheaper option [36]. For example, the combination of carbamazepine with ripovacaine was already more expensive compared to MVD after 6 months [36]. Others predicted MVD to be more cost-effective after 12 months of treatment [37]. Unfortunately, it wasn't possible to compare costs of surgical versus pharmacological treatment in our study. Although financial reasons should never be the main reason for a treatment-decision, financial factors gain in importance as costs increase and resources decline $[38,39]$.

\section{Limitations}

The limitations of our study are formed by the retrospective character and by the small study population. Next to that the variable follow-up time led to a heterogeneous analysis of outcome. Reason for this was the health care structure of the region. Long-term follow-up was usually only by the doctor in their proximity. Longer neurosurgical follow-up could thereby mean that these patients live more in the proximity of the hospital or have had symptoms. Therefor a prospective larger registry study should be conducted. Other alternatives could be telephone or internet-based follow-ups. Lastly, not all essential criteria, defined by Zakrzewska and Lopez [40] for the structured analysis of treatment of TN could be met retrospectively.

\section{Conclusion}

TN patients that were operated on earlier after symptom onset have a better chance to a better or even pain-free outcome. Therefore, each patient should be informed about all treatment options, effectiveness and risks at an early stage of disease.

\section{Ethics}

A special permission of the BAG (Federal Office of Public Health) was obtained due to the retrospective nature of this study, as well as regular approval of the local ethics committee of the Canton of St. Gall.

\section{References}

1. Obermann M (2010) Treatment options in trigeminal neuralgia. Ther Adv Neurol Disord 3: 107-115.

2. Campbell F, Graham J, Zilkha K (1966) Clinical trial of carbazepine (tegretol) in trigeminal neuralgia. J Neurol Neurosurg Psychiatry 29: 265-267.

3. Fromm G, Terrence C, Chattha A (1984) Baclofen in the treatment of trigemina neuralgia: Double-blind study and long-term follow-up. Ann Neurol 15: 240-244.

4. Tatli M, Satici O, Kanpolat Y, Sindou M (2008) Various surgical modalities for trigeminal neuralgia: Literature study of respective long-term outcomes. Acta Neurochir (Wien) 150: 243-255.

5. Zakrzewska JM, Linskey ME (2014) Trigeminal neuralgia. BMJ 348: g474.

6. Gubian A, Rosahl SK (2017) Meta-analysis on safety and efficacy of microsurgical and radiosurgical treatment of trigeminal neuralgia. World Neurosurg 103: 757-767.

7. Berger I, Nayak N, Schuster J, Lee J, Stein S, et al. (2017) Microvascular decompression versus stereotactic radiosurgery for trigeminal neuralgia: A decision analysis. Cureus 9: e1000.

8. Di Stefano G, La Cesa S, Truini A, Cruccu G (2014) Natural history and outcome of 200 outpatients with classical trigeminal neuralgia treated with carbamazepine or oxcarbazepine in a tertiary centre for neuropathic pain. $J$ Headache Pain 15: 34

9. Nunta-aree S, Patiwech K, Sitthinamsuwan B (2017) Microvascular decompression for treatment of trigeminal neuralgia: Factors that predic complete pain relief and study of efficacy and safety in older patients. World Neurosurg 2017

10. Ammori MB, King AT, Siripurapu R, Herwadkar AV, Rutherford SA (2013) Factors influencing decision-making and outcome in the surgical management of trigeminal neuralgia. J Neurol Surg B Skull Base 74: 75-781.

11. Barba D, Alksen J (1984) Success of microvascular decompression with and without prior surgical therapy for trigeminal neuralgia. J Neurosurg 60: 104-107.

12. Bederson J, Wilson C (1989) Evaluation of microvascular decompression and partial sensory rhizotomy in 252 cases of trigeminal neuralgia. J Neurosurg 71: 359.

13. Jannetta $P$ (1996) Outcome after microvascular decompression for typical trigeminal neuralgia, hemifacial spasm, tinnitus, disabling positional vertigo and glossopharyngeal neuralgia (honoured guest lecture). Clin Neurosurg 44: 331-383.

14. Zakrzewska JM, Coakham HB (2012) Microvascular decompression for trigeminal neuralgia: Update. Curr Opin Neurol 25: 296-301.

15. Li S, Pan Q, Liu N, Shen F, Liu Z, et al. (2004) Trigeminal Neuralgia: What are the important factors for good operative outcomes with microvascular decompression. Surg Neurol 62: 400-405.

16. Puca A, Meglio M, Cioni M, Visocchi M, Vari R (1993) Microvascular decompression for trigeminal neuralgia: Prognostic factors. Acta Neurochir (Wien) 58: 165-167. 
Citation: Engel DC, Fournier JY, Yetimoglu C, Haile SR (2018) Trigeminal Neuralgia Type 1: Earlier Microvascular Decompression is Associated with Improved Outcome. Int J Neurorehabilitation 5: 307. doi: 10.4172/2376-0281.1000307

17. Zakrzewska JM, Lopez BC, Kim SE, Coakham HB (2005) Patient reports of satisfaction after microvascular decompression and partial sensory rhizotomy for trigeminal neuralgia. Neurosurgery 56: 1304-1312.

18. Burchiel KJ (2003) A new classification for facial pain. Neurosurgery 53:11641167.

19. Barker F, Jannetta P, Bissonette D, Larkins M, Jho H (1996) The long-term outcome of microvascular decompression for trigeminal neuralgia. $\mathrm{N}$ Engl $\mathrm{J}$ Med 334: 1077-1083.

20. Sindou M, Leston J, Decullier E, Chapuis F (2007) Microvascular decompression for primary trigeminal neuralgia: Long-term effectiveness and prognostic factors in a series of 362 consecutive patients with clear-cut neurovascular conflicts who underwent pure decompression. J Neurosurg 107:1144-1153.

21. Cohen-Gadol A (2011) Microvascular decompression surgery for trigeminal neuralgia and hemifacial spasm: Nuances of the technique based on experiences with 100 patients and review of the literature. Clin Neurol Neurosurg 113: 844-853.

22. Sindou M, Leston JM, Decullier E, Chapuis F (2008) Microvascualr decompression for trigeminal neuralgia: The importance of a non-compressive technique - Kaplan-Meier analysis in a consecutive series of 330 patients. Neurosurgery 63: 341-651.

23. Klun B (1992) Microvascular decompression and partial sensory rhizotomy in the treatment of trigeminal neuralgia: Personal experience with 220 patients. Neurosurgery 30: 49-52.

24. Steiger $\mathrm{H}$. Pronostic factors in the treatment of trigeminal neuralgia. Analysis of a differential therapeutic approach. Acta Neurochir (Wien) 113: 11-17.

25. Sun T, Saito S, Nakai O, Ando T (1994) Long-term results of microvascular decompression for trigeminal neuralgia with reference to probability of recurrence. Acta Neurochir (Wien) 126: 144-148.

26. Zakrzewska JM, Coakham HB (2012) Microvascular decompression for trigeminal neuralgia: Update. Curr Opin Neurol 25: 296-301.

27. Pollock B, Schoeberl K (2010) Prospective comparison of posterior fossa and exploration and stereotactic radiosurgery dorsal root entry zone target as primary surgery for patients with idiopathic trigeminal neuralgia. Neurosurgery 67: 633-638.

28. Linskey M, Ratanatharathorn V, Penagaricano J (2008) A prospective cohort study of microvascular decompression and Gamma Knife surgery in patients with trigeminal neuralgia. J Neurosurg 109: S160-172.

29. Jo KW, Kong DS, Hong KS, Lee Ja, Park K (2013) Long-term prognostic factors for microvascular decompression for trigeminal neuralgia. J Clin Neurosci 20 : 440-445.

30. Sandel T, Eide PK (2013) Long-term results of microvascular decompression for trigeminal neuralgia and hemifacial spasms according to preoperative symptomatology. Acta Neurochir 155:1681-1692.

31. Miller JP, Acar F, Burchiel KJ (2009) Classification of trigeminal neuralgia Clinical, therapeutic, and prognostic implications in a series of 144 patients undergoing microvascular decompression. J Neurosurg 111: 1231-1234.

32. Rughani A, Dumont T, Lin C (2011) Safety of microvascular decompression for trigeminal neuralgia in the elderly: Clinical article. J Neurosurg 115: 202-209.

33. Ferroli P, Acerbi F, Tomei M, Tringali G, Franzini A, et al. (2010) Advanced age as a contraindication to microvascular decompression for drug-resistant trigeminal neuralgia: Evidence of prejudice? Neurol Sci 31: 23-28.

34. Pollock BE, Stien KJ (2011) Posterior fossa exploration for trigeminal neuralgia patients older than 70 years of age. Neurosurgery 69: 1255-1260.

35. Günther T, Gerganov VM, Stieglitz L, Ludemann W, Samii A, et al.(2009) Microvascular decompression for trigeminal neuralgia in the elderly: Long-term treatment outcome and comparison with younger patients. Neurosurgery 65 477-482.

36. Lemos L, Alegria C, Oliveira J, Machado A, Oliveira P, et al. (2011) Pharmacological versus microvascular decompression approaches for the treatment of trigeminal neuralgia: Clinical outcomes and direct costs. J Pain Res 4: 233-244.

37. Pollock BE, Ecker RD (2005) A prospective cost-effectiveness study of trigeminal neuralgia surgery. Clin J Pain 21: 317-322

38. Rice D (2004) Economic implications of increased longevity in the United States. Annu Rev Public Heal 25: 457-473.

39. Abel-Smith B, Mossialos E (1994) Cost containment and health care reform: A study of the European Union. Health Policy (New York) 28: 89-132.

40. Zakrzewska JM, Lopez BC (2003) Quality of reporting in evaluations of surgical treatment of trigeminal neuralgia: Recommendations for future reports. Neurosurgery 53: 110-122. 